\title{
PENGARUH MODEL JARINGAN TERHADAP OPTIMASI ROUTING OPEN SHORTEST PATH FIRST (OSPF)
}

\author{
Lady Silk $\mathbf{M}^{1}$, Suhardi ${ }^{2}$ \\ ${ }^{1}$ Akademi Teknik dan Keselamatan Penerbangan Surabaya \\ Jl. Jemur Andayani I/73 Surabaya 60236 \\ ${ }^{2}$ Jurusan Informatika Sekolah Teknik Elektro dan Informatika \\ Institut Teknologi Bandung \\ Jl. Ganesha 10, Ged. Achmad Bakrie, Labtek VIII Lt.2 Bandung 40132 \\ Email: ${ }^{1}$ ladysilkmoonlight@yahoo.co.id
}

\begin{abstract}
ABSTRAK
Routing merupakan proses mengirim data dari satu network ke network lain. Dengan dynamic routing maka mekanisme routing dilakukan secara dinamis dengan menentukan jarak terpendek secara cepat dan akurat antara peralatan pengirim dan penerima. Open Shortest Path First (OSPF) merupakan salah satu protokol dynamic routing yang menggunakan algoritma link-state untuk membangun dan menghitung jalur terpendek ke semua tujuan yang diketahui. OSPF mendistribusikan informasi routing antara router-router autonomous system (AS). OSPF memiliki titik berat pada kinerja processor, kebutuhan memori dan konsumsi bandwidth. Oleh karena itu perlu mengoptimalkan kinerja protokol routing OSPF terutama masalah pengaruh bandwith dengan menentukan model dan area jaringan routing $O S P F$.
\end{abstract}

Kata kunci : routing, rynamic routing, $O S P F$

\begin{abstract}
Data sending processes from one to the other networks is called to be Routing. Using the dynamic routing, the routing mechanism is dynamically done by swiftly and accurately determining the shortest route between sender and receiver. One of the dynamic routing protocols is the Open shortest path first $(O S P F)$ using link-state algorithm to build and count the shortest route to the all known destination. OSPF distributes routing information between system autonomous routers (AS). The focus of OSPF is in the processor activity, memory needs and bandwidth consumption. There are needs to optimize OSPF routing protocol activity by determining OSPF routing network area and model especially to the bandwidth influence.
\end{abstract}

Key words: routing, dynamic routing, $\mathrm{OSPF}$

\section{Pendahuluan}

Semakin besar suatu jaringan maka manajemen jaringan juga menjadi lebih kompleks dan rumit. Oleh karena itu perlu adanya manjemen jaringan dan proses routing yang tepat untuk menentukan jalur tercepat atau terdekat dalam mengirimkan paket-paket data sampai ke tujuannya. Aturan router dalam melakukan proses routing tersebut dikenal dengan protokol routing. Baik secara statis maupun dinamis routing harus didesain agar sangat efisien.

Konsep dasar dari routing adalah bahwa router meneruskan Internet Protokol (IP) paket berdasarkan pada IP address tujuan yang ada dalam header IP paket. Static routing adalah suatu mekanisme routing yang tergantung dengan routing table dengan konfigurasi manual. Dynamic routing adalah suatu mekanisme routing dimana pertukaran routing table antar router yang ada pada jaringan dilakukan secara dinamis. Dalam skala jaringan yang kecil yang terdiri dari dua atau tiga router saja, pemakaian static routing lebih umum dipakai.

OSPF merupakan sebuah routing protokol yang hanya dapat bekerja dalam jaringan internal di mana masih memiliki hak administrasi terhadap jaringan tersebut. OSPF juga merupakan routing protokol yang berstandar terbuka, yaitu routing protokol ini bukan ciptaan dari vendor manapun. Dengan demikian, siapapun dapat menggunakannya, perangkat manapun dapat kompatibel dengannya, dan dimanapun routing protokol ini dapat diimplementasikan. OSPF menggunakan protokol routing link-state, yang memiliki titik berat pada kinerja processor, kebutuhan memori dan konsumsi bandwidth.

Setiap protokol routing memiliki kelebihan dan kekurangan masing-masing. Routing Information Protocol (RIP) dan OSPF salah satu dari dynamic routing. Namun OSPF lebih baik daripada RIP, karena RIP dapat menimbulkan routing loop dan menggunakan bandwith yang lebih besar (Syafrizal, 2008). 
Dengan beberapa kelebihan routing protokol OSPF, sehingga dalam studi kasus ini digunakan routing OSPF. Oleh karena itu perlu mengoptimalkan kinerja Protokol Routing OSPF terutama masalah pengaruh bandwith dengan menentukan model dan area jaringan routing OSPF untuk mengoptimalkan kinerjanya dan meminimalkan beban yang ada.

Dapat dirumuskan masalah pada penelitian ini yaitu bagaimana menerapkan protokol routing OSPF pada suatu jaringan dengan menentukan model topologi dan area jaringan yang tepat, sehingga dapat menekan konsumsi bandwidth. Untuk membatasi ruang lingkup yang akan dibahas pada penelitian ini, maka digunakan 8 buah router yang masing masing terhubung dengan 1 buah komputer. Sehingga tujuan yang akan dicapai yaitu penerapan protokol routing OSPF pada suatu jaringan dapat optimal.

\section{Tinjauan Pustaka}

\subsection{Routing}

Routing adalah proses menentukan rute dari host asal ke host tujuan (Lin dkk., 2011). Routing merupakan proses memindahkan data dari satu network ke network lain dengan cara mem-forward paket data via gateway. Routing menentukan kemana datagram akan dikirim agar mencapai tujuan yang diinginkan (Sofana, 2008). Informasi yang dibutuhkan router dalam melakukan routing yaitu:

a. Alamat tujuan/ destination address

b. Mengenal sumber informasi

c. Menemukan rute

d. Pemilihan rute

e. Menjaga informasi routing

Sebuah router mempelajari informasi routing dari mana sumber dan tujuannya yang kemudian ditempatkan pada tabel routing. Router akan berpatokan pada tabel ini, untuk memberitahu port yang akan digunakan untuk meneruskan paket ke alamat tujuan. Ada dua cara untuk memberitahu router bagaimana cara meneruskan paket ke jaringan yang tidak terhubung langsung (not directly connected) di badan router.

\subsection{Protokol Routing}

Routing protokol adalah komunikasi antara router-router. Routing protokol mengijinkan router-router untuk sharing informasi tentang jaringan dan koneksi antar router. Router menggunakan informasi ini untuk membangun dan memperbaiki tabel routing-nya. Berikut ini merupakan keuntungan dari static route:

a. Static route lebih aman dibanding dynamic route,

b. Static route kebal dari segala usaha hacker melakukan configure router untuk tujuan membajak traffic,

c. Processor lebih ringan, dan

d. Menghemat bandwith yang dipakai karena tidak ada pertukaran data table antar router.

Akan tetapi, terdapat pula beberapa kerugian, antara lain:

a. Administrasinya cukup rumit dibanding dynamic routing jika terdiri dari banyak router yang perlu dikonfigur secara manual,

b. Rentan terhadap kesalahan saat entry data static route dengan cara manual,

c. Jika jaringan besar maka mekanisme ini akan sangat tidak efisien karena harus dilakukan pada setiap router,

d. Apabila ada perubahan atau penambahan sumber daya di dalam jaringan maka table routing juga harus segera diubah secara manual, dan

e. Informasi dari tiap router harus diketahui oleh administrator.

Dinamic routing adalah proses pengisian data routing pada routing table secara otomatis. Apabila jaringan memiliki lebih dari satu kemungkinan rute untuk tujuan yang sama maka perlu digunakan dynamic routing. Protokol routing mengatur router-router sehingga dapat berkomunikasi satu dengan yang lain dan memberikan informasi routing yang dapat mengubah isi forwarding table, tergantung keadaan jaringannya. Sehingga router-router dapat mengetahui keadaan jaringan yang terakhir dan mampu meneruskan datagram.

Untuk mempresentasikan arah Dynamic routing mengunakan nilai metric yang didalamnya terdapat parameter-parameter untuk menghasilkan nilai metric tersebut. Parameter yang dapat digunakan untuk menghasilkan sebuh nilai metric adalah: 
a. Hop count, berdasarkan banyaknya router yang dilewati

b. Ticks, berdasarkan waktu yang diperlukan

c. Cost, berdasarkan perbandingan sebua nilai standart dengan banwith yang tersedia Composite metic, berdasarkan hasil perhitungan dari parameter-parameter yaitu bandwith, delay, load, reliability.

Keuntungan Routing dinamis yaitu (Sofana, 2008):

a. Lebih mudah dikelola, karena tidak banyak memerlukan konfigurasi manual.

b. Dapat beradaptasi terhadap perubahan kondisi internetwork.

c. Route ditentukan berdasarkan informasi dari router lain.

\subsubsection{Distance vector}

Algoritma routing Distance vector secara periodik menyalin table routing dari router ke router. Perubahan tabel routing ini di-update antar router yang saling berhubungan pada saat terjadi perubahan topologi. Algoritma Distance vector juga disebut dengan algoritma Bellman-Ford. Setiap router menerima table routing dari router tetangga yang terhubung langsung.

\subsubsection{Link state routing}

Algoritma link-state juga dikenal dengan algoritma Dijkstra atau algoritma shortest path first (SPF). Algoritma ini memperbaiki informasi database dari informasi topologi. Algoritma Distance vector memiliki informasi yang tidak spesifik tentang distance network dan tidak mengetahui jarak router. Sedangkan algortima link-state memperbaiki pengetahuan dari jarak router dan bagaimana mereka interkoneksi. Link-state advertisement (LSA) adalah paket kecil dari informasi routing yang dikirim antar router. Topological database adalah kumpulan informasi yang dari LSA-LSA. Routing table adalah daftar rute dan interface. Ada beberapa titik berat yang berhubungan dengan protokol link-state, antara lain:

a. Processor overhead

b. Kebutuhan memori

c. Konsumsi bandwidth

Router-router yang menggunakan protokol link-state membutuhkan memori lebih dan proses data yang lebih daripada router-router yang menggunakan protokol Distance vector. Router link-state membutuhkan memori yang cukup untuk menangani semua informasi dari database, pohon topologi dan table routing.

\subsection{Static Routing dan Dynamic Routing}

Static routing yaitu suatu routing dimana informasi table routing di entry atau dibentuk secara manual oleh Administrator, dan harus memperbarui rute statis ini secara manual ketika terjadi perubahan topologi antar jaringan (internetwork). (Sofana, 2008).

\subsection{OSPF (Open Shortest Path First)}

OSPF bekerja berdasarkan algoritma Shortest Path First yang dikembangkan berdasarkan algoritma Dijkstra. Sebagai Interior Gateway protocol (IGP). Interior Gateway protocol atau Interior Routing Protokol dikembangkan untuk menghubungkan router-router dibawah kendali administrator jaringan (Sofana, 2008). OSPF mendistribusikan informasi routing-nya di dalam router-router yang tergabung ke dalam suatu AS. AS adalah jaringan yang dikelola oleh administrator setempat. OSPF menggunakan protokol routing link-state, didesain untuk bekerja dengan sangat efisien dalam proses pengiriman update informasi rute. OSPF merupakan protokol alternatif untuk menutupi kelemahan RIP. OSPF juga merupakan protokol routing yang menggunakan prinsip multipath (multi path protokol) dapat mempelajari berbagai rute dan memilih lebih dari satu rute ke host tujuan.

OSPF digunakan bersamaan dengan IP, maksudnya paket OSPF dikirim bersamaan dengan header paket data IP. Setiap router OSPF mempunyai database yang identik yang menggambarkan topologi suatu Autonomous System yang disebut dengan Link State database (Topological database). Dari database ini, perhitungan Shortest Path First dilakukan untuk membentuk Routing Table. Perhitungan ulang terhadap Shortest Path First dilakukan apabila terjadi perubahan pada topologi jaringan. OSPF memungkinkan beberapa jaringan untuk dikelompokkan bersama. Pengelompokkan seperti ini dinamakan dengan area dan topologinya tersembunyi dari seluruh AS. Informasi yang tersembunyi ini memungkinkan penurunan traffic routing. Dengan menggunakan konsep area sistem penyebaran informasinya menjadi lebih teratur dan tersegmentasi. Dengan adanya distribusi routing yang teratur, 
maka penggunaan bandwidth akan lebih efisien, lebih cepat mencapai konvergensi, dan lebih presisi dalam menentukan rute terbaik dalam mengirim paket (Syafrizal, 2008).

\section{Metode Penelitian}

Metode penelitian yang digunakan yaitu observasi dan pengumpulan data, analisis kebutuhan dan perancangan, proses implementasi dan pengujian. Pada tahap observasi dan pengumpulan data, dilakukan pengumpulan materi dan pembelajaran mengenai prinsip kerja dynamic routing dan protokol routing OSPF. Kemudian pada tahap analisis kebutuhan dan perancangan, dilakukan proses analisis terhadap kebutuhan software dan hardware yang dibutuhkan serta perancangan sistem yang akan dibangun, berdasarkan hasil studi literatur yang ada. Dalam tahapan proses implementasi dan pengujian dilakukan dari perancangan yang telah dibuat sebelumnya, mulai dari instalasi hingga pengujian sistem menggunakan traffic load untuk menentukan hasil optimalisasi sistem.

\section{Hasil dan Pembahasan}

\subsection{Desain Sistem}

Tahap model konseptual sistem terdiri dari desain topologi, konfigurasi area routing OSPF dan pengujian. Untuk implementasinya digunakan Packet tracer. Packet tracer merupakan sebuah software yang digunakan untuk melakukan simulasi jaringan. Software ini dikembangkan oleh sebuah perusahaan yang bergerak dalam masalah jaringan yaitu Cisco.

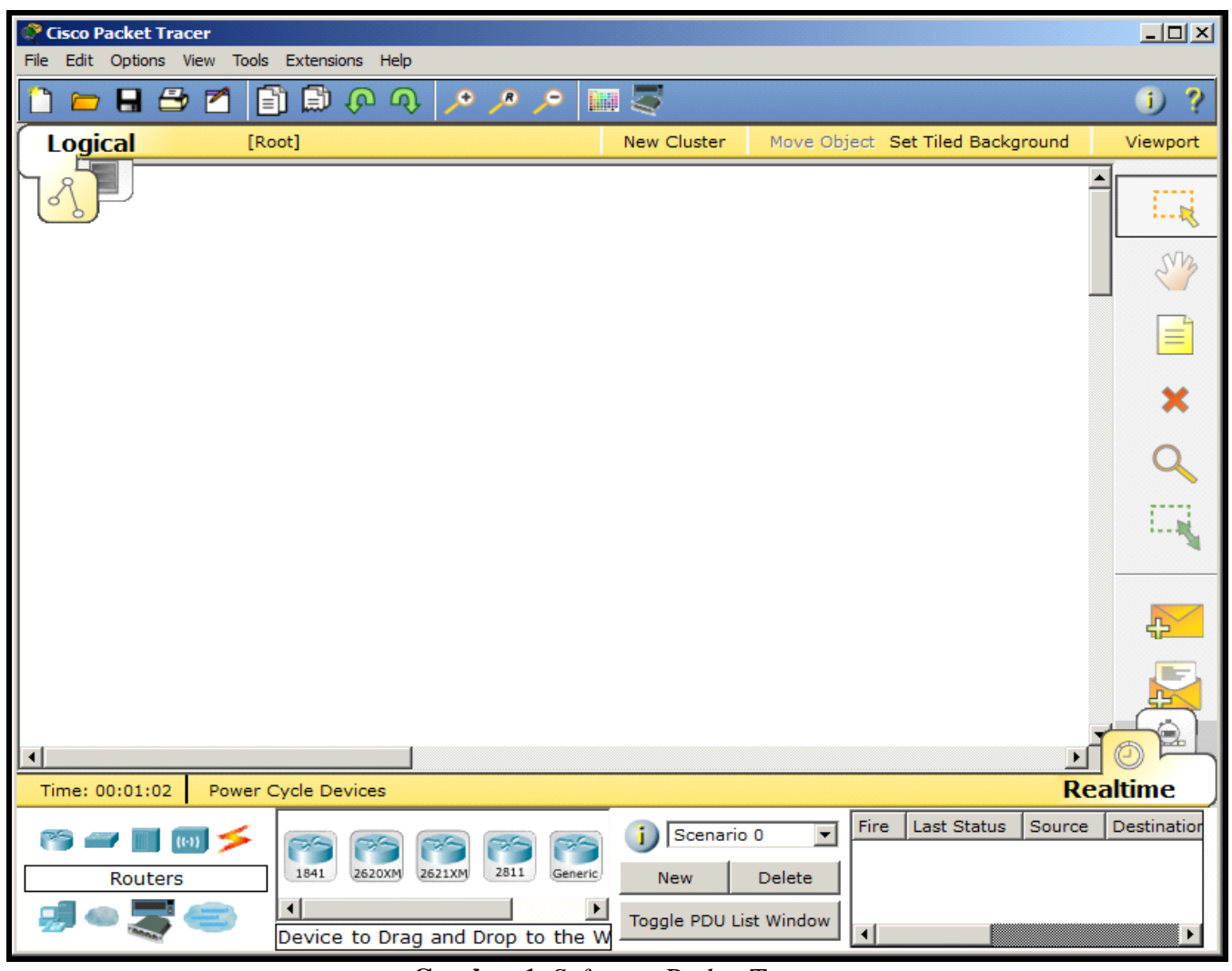

Gambar 1. Software Packet Tracer

Tahap-tahap proses implementasi ditunjukkan melalui Gambar 2. 


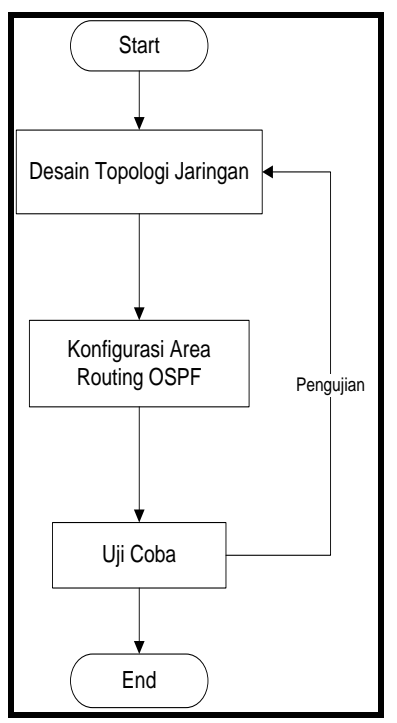

Gambar 2. Flowchart desain Sistem

\subsection{Desain Topologi dan Konfigurasi Jaringan}

Untuk menentukan model Jaringan OSPF yang optimal, maka dilakukan desain topologi dan area jaringan, serta konfigurasi routing OSPF yang berbeda-beda. Percobaan ini dilakukan dengan 8 buah router dan 1 buah Komputer yang masing-masing terhubung dengan router. Dengan OSPF, maka jaringan akan dibagi menjadi tingkatan yang dinamakan sistem pengelompokan area. Berikut ini merupakan konfigurasi masing-masing Komputer:

Tabel 1. Konfigurasi KOMPUTER

\begin{tabular}{|c|c|c|c|}
\hline Nama KOMPUTER & IP & Gateway & Router \\
\hline PC 1 & 192.168 .10 .2 & 192.168 .10 .1 & Router 1 \\
\hline PC 2 & 192.168 .20 .2 & 192.168 .20 .1 & Router 2 \\
\hline PC 3 & 192.168 .30 .2 & 192.168 .30 .1 & Router 3 \\
\hline PC 4 & 192.168 .40 .2 & 192.168 .40 .1 & Router 4 \\
\hline PC 5 & 192.168 .50 .2 & 192.168 .50 .1 & Router 5 \\
\hline PC 6 & 192.168 .60 .2 & 192.168 .60 .1 & Router 6 \\
\hline PC 7 & 192.168 .70 .2 & 192.168 .70 .1 & Router 7 \\
\hline PC 8 & 192.168 .80 .2 & 192.168 .80 .1 & Router 8 \\
\hline
\end{tabular}

\subsubsection{Jaringan Single area}

Model jaringan Single area OSPF hanya terdiri dari 1 area yaitu area 0 . Gambar 3 berikut ini menunjukkan desain topologi dari single area OSPF:

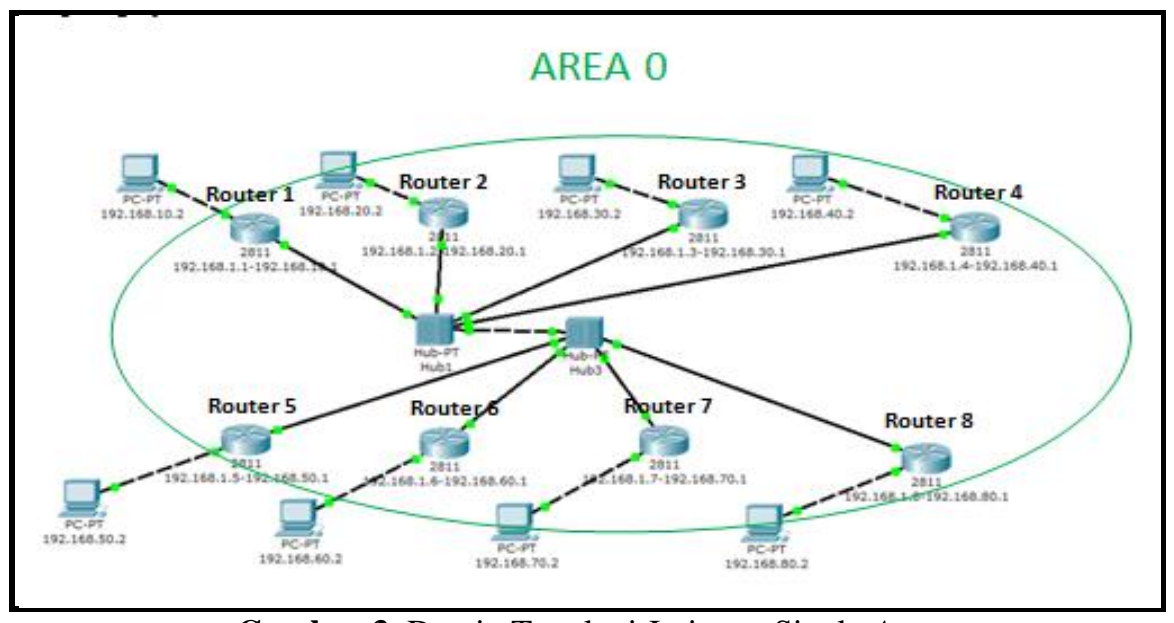

Gambar 3. Desain Topologi Jaringan Single Area 
Konfigurasi Routing OSPF Single Area ditunjukkan melalui Tabel 2 berikut ini:

Tabel 2. Konfigurasi Routing OSPF Single Area

\begin{tabular}{|c|c|}
\hline Router 1 & $\begin{array}{l}\text { Router>en } \\
\text { Router\#configteminal } \\
\text { Router(config)\#router ospf } 1 \\
\text { Router(config-router)\#network } 192.168 .10 .00 .0 .0 .255 \text { area } 0 \\
\text { Router(config-router)\#network } 192.168 .1 .00 .0 .0 .255 \text { area } 0 \\
\text { Router(config-router)\# } Z \\
\text { Router\#wr } \\
\text { Building configuration... } \\
\text { [OK] }\end{array}$ \\
\hline Router 2 & $\begin{array}{l}\text { Router(config)\#router ospf } 1 \\
\text { Router(config-router)\#network } 192.168 .20 .00 .0 .0 .255 \text { area } 0 \\
\text { Router(config-router)\#network } 192.168 .1 .00 .0 .0 .255 \text { area } 0\end{array}$ \\
\hline Router 3 & $\begin{array}{l}\text { Router(config) } \# \text { router ospf } 1 \\
\text { Router(config-router) } \# \text { network } 192.168 .30 .00 .0 .0 .255 \text { area } 0 \\
\text { Router(config-router) } \# \text { network } 192.168 .1 .00 .0 .0 .255 \text { area } 0\end{array}$ \\
\hline Router 4 & $\begin{array}{l}\text { Router(config)\#router ospf } 1 \\
\text { Router(config-router)\#network } 192.168 .40 .00 .0 .0 .255 \text { area 0 } \\
\text { Router(config-router)\#network } 192.168 .1 .00 .0 .0 .255 \text { area 0 }\end{array}$ \\
\hline Router 5 & $\begin{array}{l}\text { Router(config)\#router ospf } 1 \\
\text { Router(config-router)\#network } 192.168 .50 .00 .0 .0 .255 \text { area 0 } \\
\text { Router(config-router)\#network } 192.168 .1 .00 .0 .0 .255 \text { area 0 }\end{array}$ \\
\hline Router 6 & $\begin{array}{l}\text { Router(config) } \# \text { router ospf } 1 \\
\text { Router(config-router)\#network } 192.168 .60 .00 .0 .0 .255 \text { area } 0 \\
\text { Router(config-router)\#network } 192.168 .1 .00 .0 .0 .255 \text { area } 0\end{array}$ \\
\hline Router 7 & $\begin{array}{l}\text { Router(config)\#router ospf } 1 \\
\text { Router(config-router)\#network } 192.168 .70 .00 .0 .0 .255 \text { area 0 } \\
\text { Router(config-router)\#network } 192.168 .1 .00 .0 .0 .255 \text { area 0 }\end{array}$ \\
\hline Router 8 & $\begin{array}{l}\text { Router(config)\#router ospf } 1 \\
\text { Router(config-router)\#network } 192.168 .80 .00 .0 .0 .255 \text { area } 0 \\
\text { Router(config-router)\#network } 192.168 .1 .00 .0 .0 .255 \text { area } 0\end{array}$ \\
\hline
\end{tabular}

\subsubsection{Jaringan 3 Area}

Model jaringan 3 area OSPF terdiri dari 3 area yaitu area 0 , area 1 dan area 2 . Berikut desain topologinya:

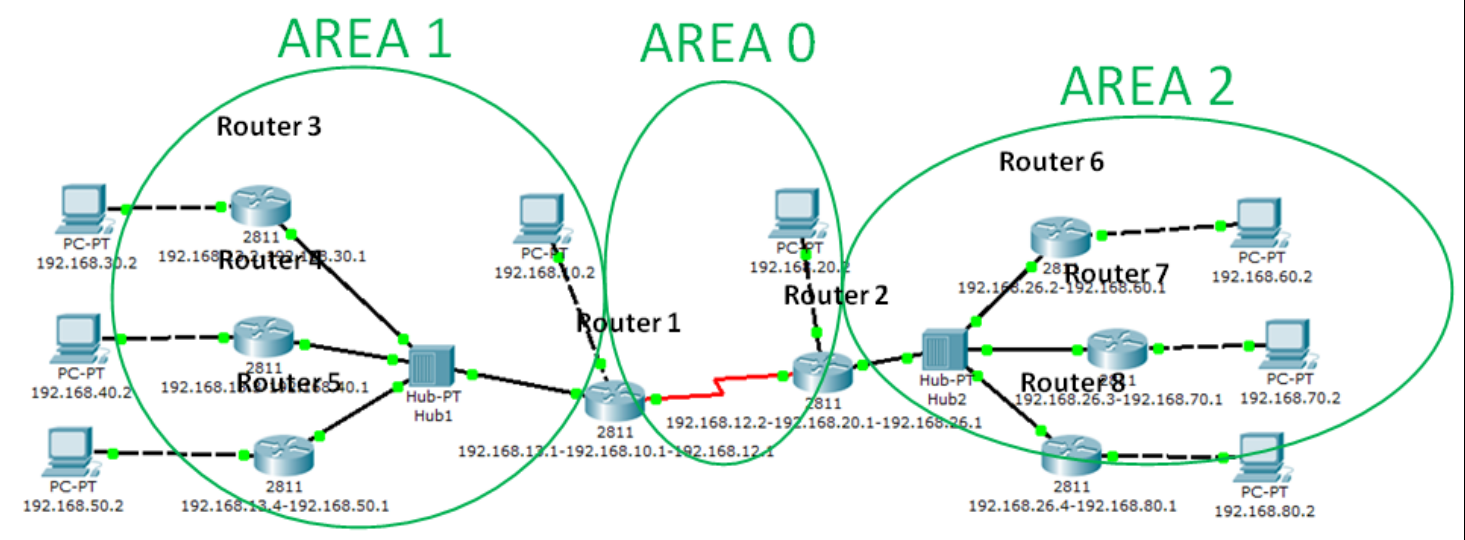

Gambar 4. Desain Topologi Jaringan 3 Area 
Konfigurasi Routing OSPF Single Area ditunjukkan melalui Table 3 berikut ini:

Tabel 3. Konfigurasi Routing OSPF 3 Area

\begin{tabular}{|c|c|}
\hline Router 1 & $\begin{array}{l}\text { Router>en } \\
\text { Router\#config terminal } \\
\text { Router(config)\#router ospf } 1 \\
\text { Router(config-router)\#network 192.168.10.0 0.0.0.255 area 0 } \\
\text { Router(config-router)\#network 192.168.12.0 0.0.0.255 area 0 } \\
\text { Router(config-router)\#network 192.168.13.0 0.0.0.255 area 0 } \\
\text { Router(config-router)\#network 192.168.145.0 0.0.0.255 area 1 } \\
\text { Router(config-router)\#^Z } \\
\text { Router\#wr } \\
\text { Building configuration... } \\
{[\mathrm{OK}]}\end{array}$ \\
\hline Router 2 & $\begin{array}{l}\text { Router(config)\#router ospf } 1 \\
\text { Router(config-router)\#network } 192.168 .20 .00 .0 .0 .255 \text { area } 0 \\
\text { Router(config-router)\#network 192.168.12.0 0.0.0.255 area 0 } \\
\text { Router(config-router)\#network 192.168.23.0 0.0.0.255 area 0 } \\
\text { Router(config-router)\#network 192.168.67.0 0.0.0.255 area 2 }\end{array}$ \\
\hline Router 3 & $\begin{array}{l}\text { Router(config)\#router ospf } 1 \\
\text { Router(config-router)\#network } 192.168 .30 .00 .0 .0 .255 \text { area } 0 \\
\text { Router(config-router)\#network } 192.168 .23 .00 .0 .0 .255 \text { area } 0 \\
\text { Router(config-router)\#network } 192.168 .13 .00 .0 .0 .255 \text { area } 0 \\
\text { Router(config-router)\#network 192.168.38.0 0.0.0.255 area 3 }\end{array}$ \\
\hline Router 4 & $\begin{array}{l}\text { Router(config)\#router ospf } 1 \\
\text { Router(config-router)\#network 192.168.40.0 0.0.0.255 area } 1 \\
\text { Router(config-router)\#network 192.168.145.0 0.0.0.255 area } 1\end{array}$ \\
\hline Router 5 & $\begin{array}{l}\text { Router(config)\#router ospf } 1 \\
\text { Router(config-router)\#network 192.168.50.0 0.0.0.255 area } 1 \\
\text { Router(config-router)\#network 192.168.145.0 0.0.0.255 area } 1\end{array}$ \\
\hline Router 6 & $\begin{array}{l}\text { Router(config)\#router ospf } 1 \\
\text { Router(config-router)\#network 192.168.60.0 0.0.0.255 area } 2 \\
\text { Router(config-router)\#network 192.168.67.0 0.0.0.255 area } 2\end{array}$ \\
\hline Router 7 & $\begin{array}{l}\text { Router(config)\#router ospf } 1 \\
\text { Router(config-router)\#network 192.168.70.0 0.0.0.255 area } 2 \\
\text { Router(config-router)\#network 192.168.67.0 0.0.0.255 area } 2\end{array}$ \\
\hline Router 8 & $\begin{array}{l}\text { Router(config)\#router ospf } 1 \\
\text { Router(config-router)\#network 192.168.80.0 0.0.0.255 area } 3 \\
\text { Router(config-router)\#network 192.168.38.0 0.0.0.255 area } 3\end{array}$ \\
\hline
\end{tabular}

\subsubsection{Jaringan 5 Area}

Model jaringan 4 area OSPF terdiri dari 4 area yaitu area 0 , area 1 , area 2, dan area 3 . Berikut desain topologinya:

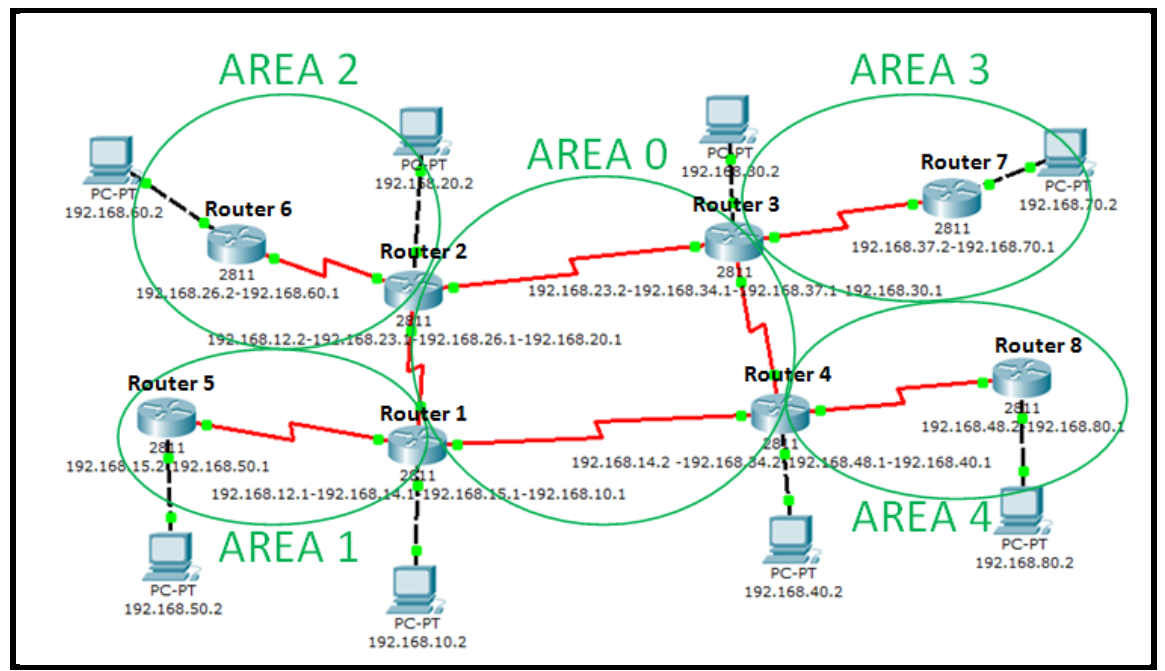

Gambar 5. Desain Topologi Jaringan 5 Area 
Tabel 4. Konfigurasi Routing OSPF 5 Area

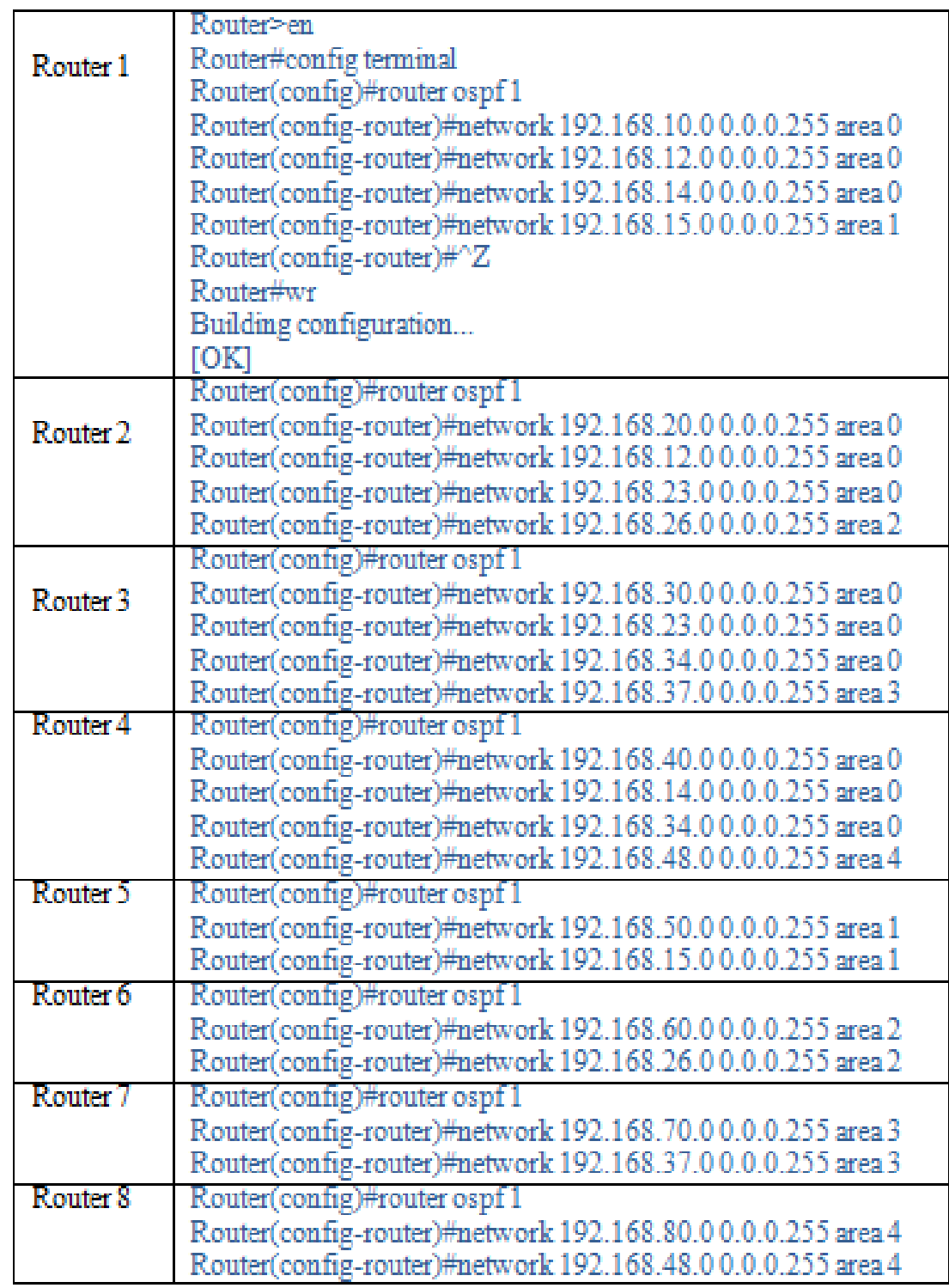

\section{IP route pada Router 1 :}

Router>show ip route

Codes: C - connected, S - static, I - IGRP, R - RIP, M - mobile, B - BGP

D - EIGRP, EX - EIGRP external, O - OSPF, IA - OSPF inter area

N1 - OSPF NSSA external type 1, N2 - OSPF NSSA external type 2

E1 - OSPF external type 1, E2 - OSPF external type 2, E - EGP

i - IS-IS, L1 - IS-IS level-1, L2 - IS-IS level-2, ia - IS-IS inter

area

* - candidate default, U - per-user static route, o - ODR

P - periodic downloaded static route

Gateway of last resort is not set

C 192.168.10.0/24 is directly connected, Fastethernet0/0

C 192.168.14.0/24 is directly connected, Serialo/0/1

C $\quad 192.168 .15 .0 / 24$ is directly connected, Serial0/1/0

$192.168 .20 .0 / 24$ [110/193] via 192.168.14.2, 00:00:48, Serial0/0/1

$192.168 .23 .0 / 24[110 / 192]$ via 192.168.14.2, 00:00:48, Serial0/0/1

IA 192.168.26.0/24[110/256] via 192.168.14.2, 00:00:48, Serial0/0/1

$192.168 .30 .0 / 24[110 / 129]$ via 192.168.14.2, 00:00:48, Serial0/0/1

$192.168 .34 .0 / 24[110 / 128]$ via 192.168.14.2, 00:00:48, Serial0/0/1

IA 192.168.37.0/24 [110/192] via 192.168.14.2, 00:00:48, Serial0/0/1

o 192.168.40.0/24 [110/65] via 192.168.14.2, 00:00:48, Serial0/0/1 
O IA 192.168.48.0/24 [110/128] via 192.168.14.2, 00:00:48, Serial0/0/1

$192.168 .50 .0 / 24[110 / 65]$ via 192.168.15.2, 00:01:03, Serial0/1/0

O IA 192.168.60.0/24 [110/257] via 192.168.14.2, 00:00:48, Serial0/0/1

O IA 192.168.70.0/24 [110/193] via 192.168.14.2, 00:00:48, Serial0/0/1

O IA 192.168.80.0/24 [110/129] via 192.168.14.2, 00:00:48, Serial0/0/1

Network Tetangga Router 1 :

Router>show ip ospf neighbor

$\begin{array}{lrllll}\text { Neighbor ID } & \text { Pri } & \text { State } & \text { Dead Time } & \text { Address } & \text { interface } \\ 192.168 .48 .1 & 0 & \text { FULL/ - } & 00: 00: 36 & 192.168 .14 .2 & \text { Serial0/0/1 } \\ 192.168 .50 .1 & 0 & \text { FULL/ - } & 00: 00: 33 & 192.168 .15 .2 & \text { Serial0/1/0 }\end{array}$

Database Network Router1:

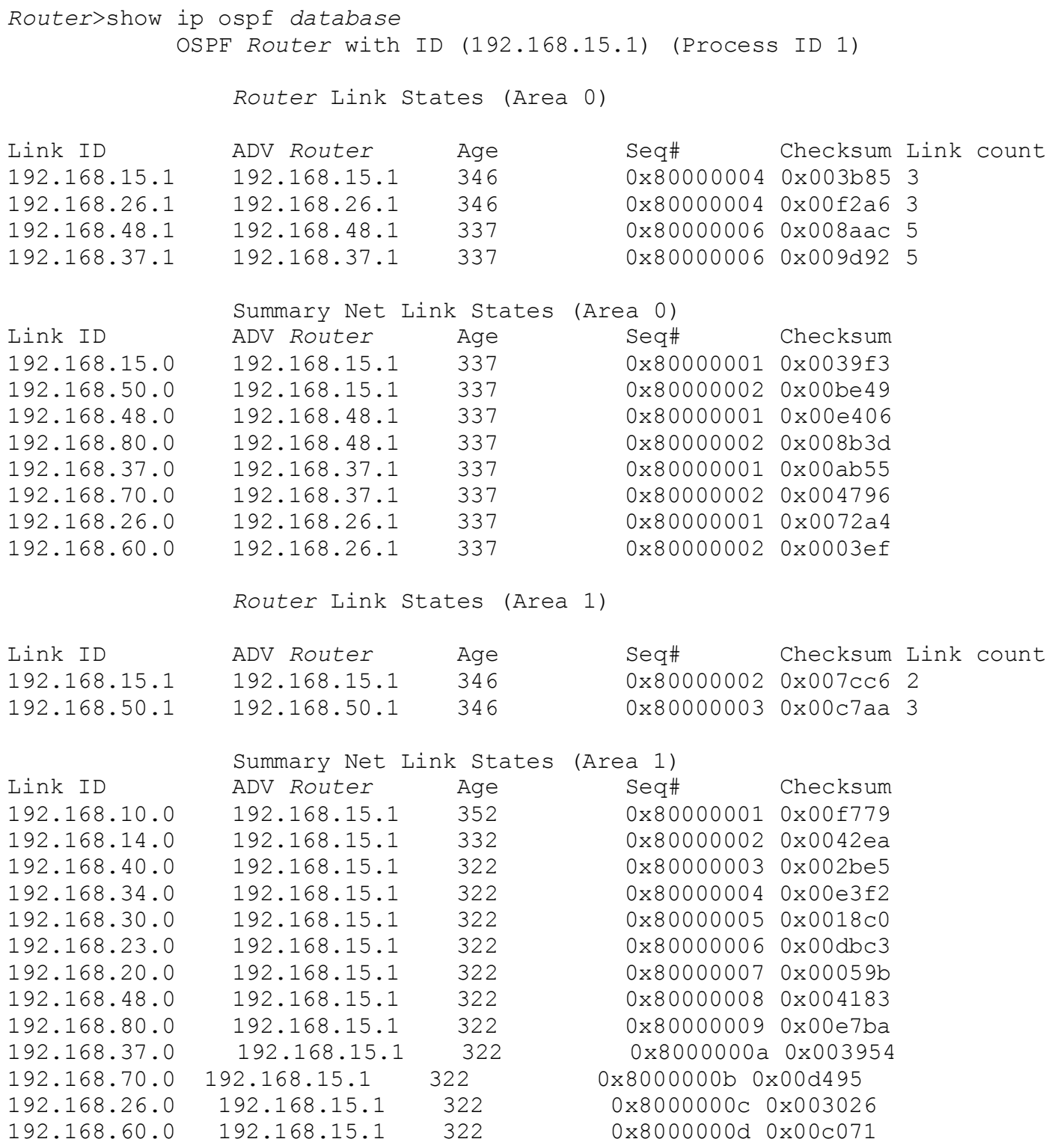

\section{Pengujian}

Pengujian dilakukan menggunakan simulasi Traffic Generator pada Desktop masing-masing Komputer.

Pengujian dilakukan dengan mengirimkan paket antar Komputer menggunakan application Ping dan FTP dengan beban tertentu dan interval periodik tertentu sebagai simulasi penerapan Traffic load. Dari simulasi tersebut, dilakukan pencatatan waktu (time) yang dibutuhkan dalam pengiriman paket. Dari hasil time tersebut dapat dilakukan analisa untuk mencapai kesimpulan. 


\subsection{Aplikasi Ping}

Disikan nilai TTL (Time to Live) yaitu 255, nilai TOS (Time of Service) yaitu 255, Sequence Number 1 dan size untuk beban 14000 bit. TTL merupakan lama waktu paket saat mengirim hingga sampai lagi. Setting ini berlaku untuk setiap Komputer pada semua model area yang akan diujikan.

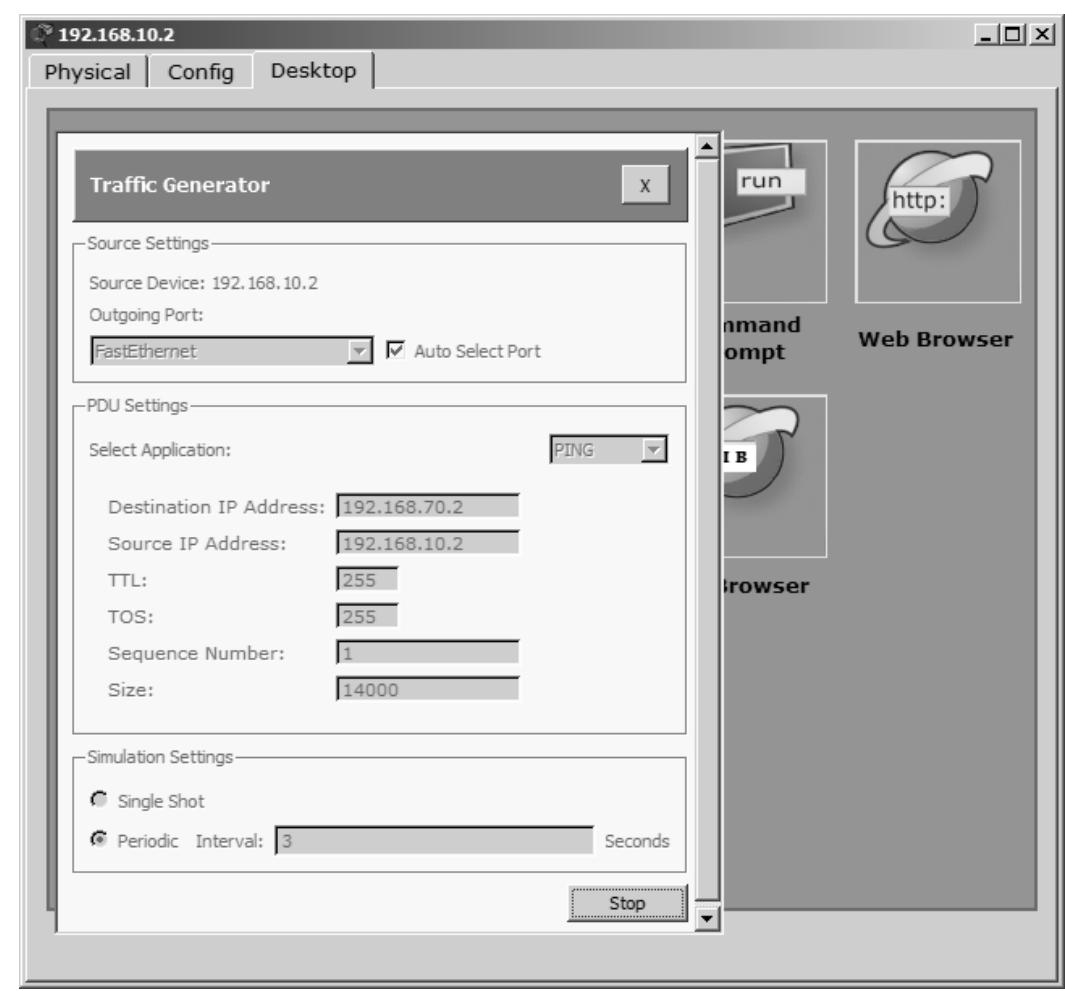

Gambar 6. Traffic Genarator Desktop Komputer

Namun pada Destination IP address dan Souce IP Address disesuaikan seperti yang ditunjukkan melalui Tabel 5.

Tabel 5. Tabel IP Komputer asal dan tujuan pengiriman paket

\begin{tabular}{|c|c|}
\hline Source IP Address & Destination IP Address \\
\hline 192.168 .10 .2 & 192.168 .70 .2 \\
\hline 192.168 .20 .2 & 192.168 .80 .2 \\
\hline 192.168 .30 .2 & 192.168 .10 .2 \\
\hline 192.168 .40 .2 & 192.168 .20 .2 \\
\hline 192.168 .50 .2 & 192.168 .30 .2 \\
\hline 192.168 .60 .2 & 192.168 .40 .2 \\
\hline 192.168 .70 .2 & 192.168 .50 .2 \\
\hline 192.168 .80 .2 & 192.168 .60 .2 \\
\hline
\end{tabular}

Pada Simulation Settings, Periodic Interval dapat diisikan 3 second, sehingga proses pengiriman data akan berulang 3 detik sekali. Lakukan hal yang sama pada semua Komputer sehingga dapat terjadi traffic load pada Jaringan. 


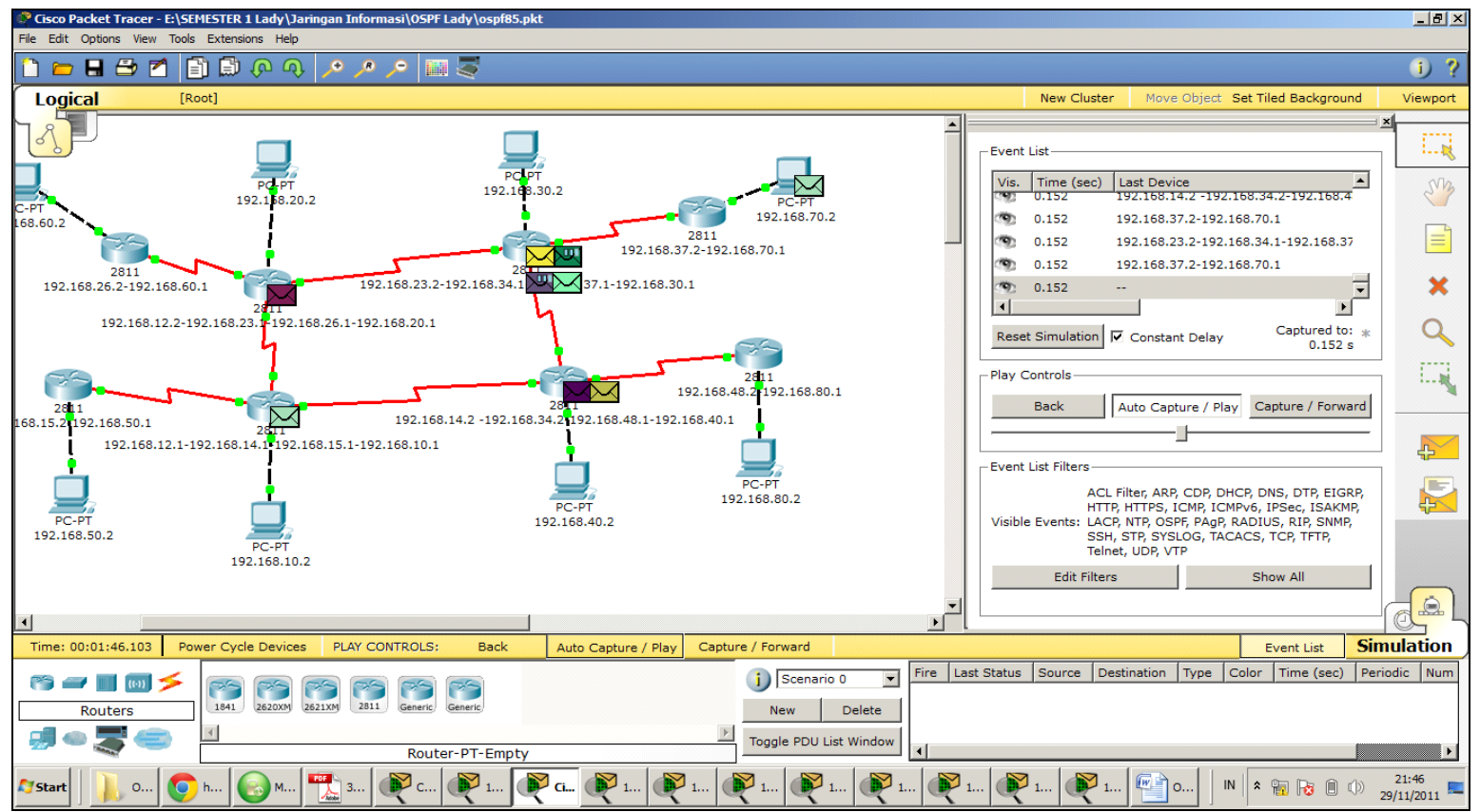

Gambar 7. Traffic load pada Jaringan

Dari Traffic load diatas, dapat dilihat waktu yang dibutuhkan untuk mengirim paket antar Komputer untuk masing-masing area sebagai berikut:

Tabel 6. Hasil Waktu

\begin{tabular}{|c|c|c|c|c|c|}
\hline \multirow[t]{2}{*}{ Source IP Address } & \multirow[t]{2}{*}{ Destination IP Address } & \multicolumn{4}{|c|}{ TIME (SECOND) MODEL OSPF } \\
\hline & & 1 Area & 3 Area & 4 Area & 5 Area \\
\hline 192.168 .10 .2 & 192.168 .70 .2 & 0.012 & 0.012 & 0.010 & 0.010 \\
\hline 192.168.20.2 & 192.168 .80 .2 & 0.012 & 0.010 & 0.010 & 0.010 \\
\hline 192.168 .30 .2 & 192.168 .10 .2 & 0.012 & 0.010 & 0.008 & 0.008 \\
\hline 192.168 .40 .2 & 192.168 .20 .2 & 0.012 & 0.012 & 0.010 & 0.008 \\
\hline 192.168 .50 .2 & 192.168 .30 .2 & 0.012 & 0.010 & 0.010 & 0.010 \\
\hline 192.168 .60 .2 & 192.168 .40 .2 & 0.012 & 0.012 & 0.012 & 0.010 \\
\hline 192.168 .70 .2 & 192.168.50.2 & 0.012 & 0.012 & 0.012 & 0.012 \\
\hline 192.168 .80 .2 & 192.168 .60 .2 & 0.012 & 0.010 & 0.012 & 0.012 \\
\hline \multicolumn{2}{|c|}{ Rata-rata } & 0.012 & 0.011 & 0.0105 & 0.010 \\
\hline
\end{tabular}

\subsection{Aplikasi FTP}

Disikan nilai TTL (Time to Live) yaitu 255, nilai TOS (Time of Service) yaitu 255, source port 80, destination port 21 dan size 10000 bit. Setting ini berlaku untuk setiap Komputer pada semua model area yang akan diujikan. 


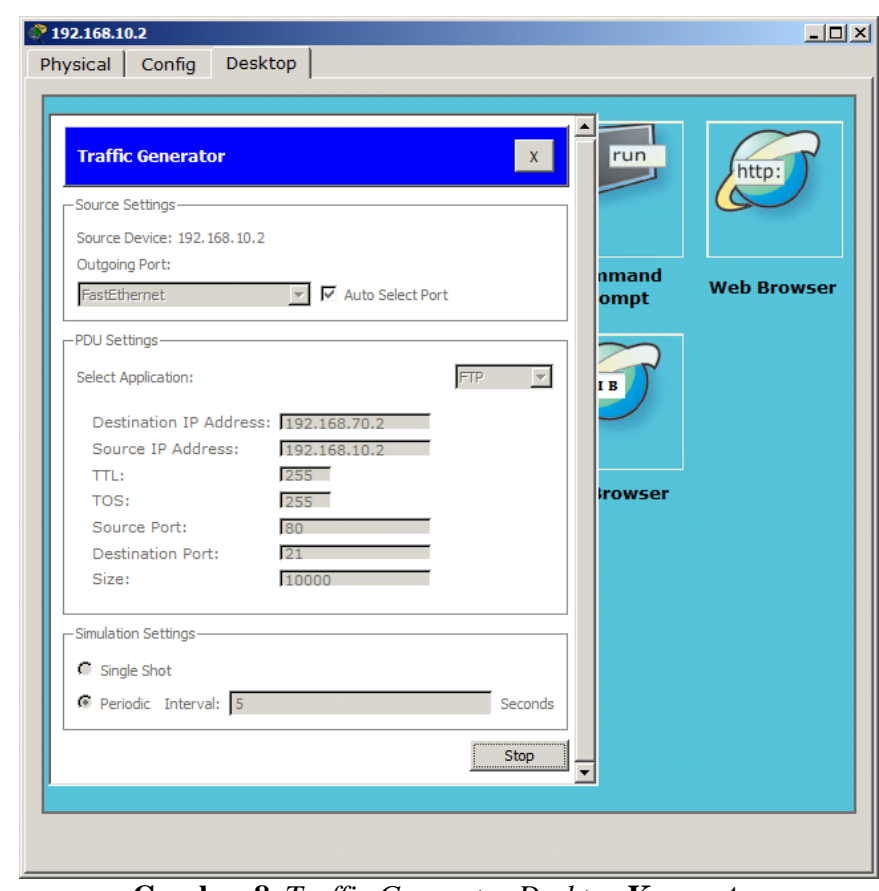

Gambar 8. Traffic Genarator Desktop Komputer

Namun pada Destination IP address dan Souce IP Address disesuaikan sebagai berikut:

Tabel 7. Tabel IP Komputer asal dan tujuan pengiriman paket

\begin{tabular}{|c|c|}
\hline Source IP Address & Destination IP Address \\
\hline 192.168 .10 .2 & 192.168 .70 .2 \\
\hline 192.168 .20 .2 & 192.168 .80 .2 \\
\hline 192.168 .30 .2 & 192.168 .10 .2 \\
\hline 192.168 .40 .2 & 192.168 .20 .2 \\
\hline 192.168 .50 .2 & 192.168 .30 .2 \\
\hline 192.168 .60 .2 & 192.168 .40 .2 \\
\hline 192.168 .70 .2 & 192.168 .50 .2 \\
\hline 192.168 .80 .2 & 192.168 .60 .2 \\
\hline
\end{tabular}

Pada Simulation Settings, Periodic Interval dapat diisikan 5 second, sehingga proses pengiriman data akan berulang 5 detik sekali. Lakukan hal yang sama pada semua Komputer sehingga dapat terjadi traffic load pada Jaringan. Simulasi Traffic load Aplication FTP hampir sama dengan Simulasi Traffic load Aplication Ping.

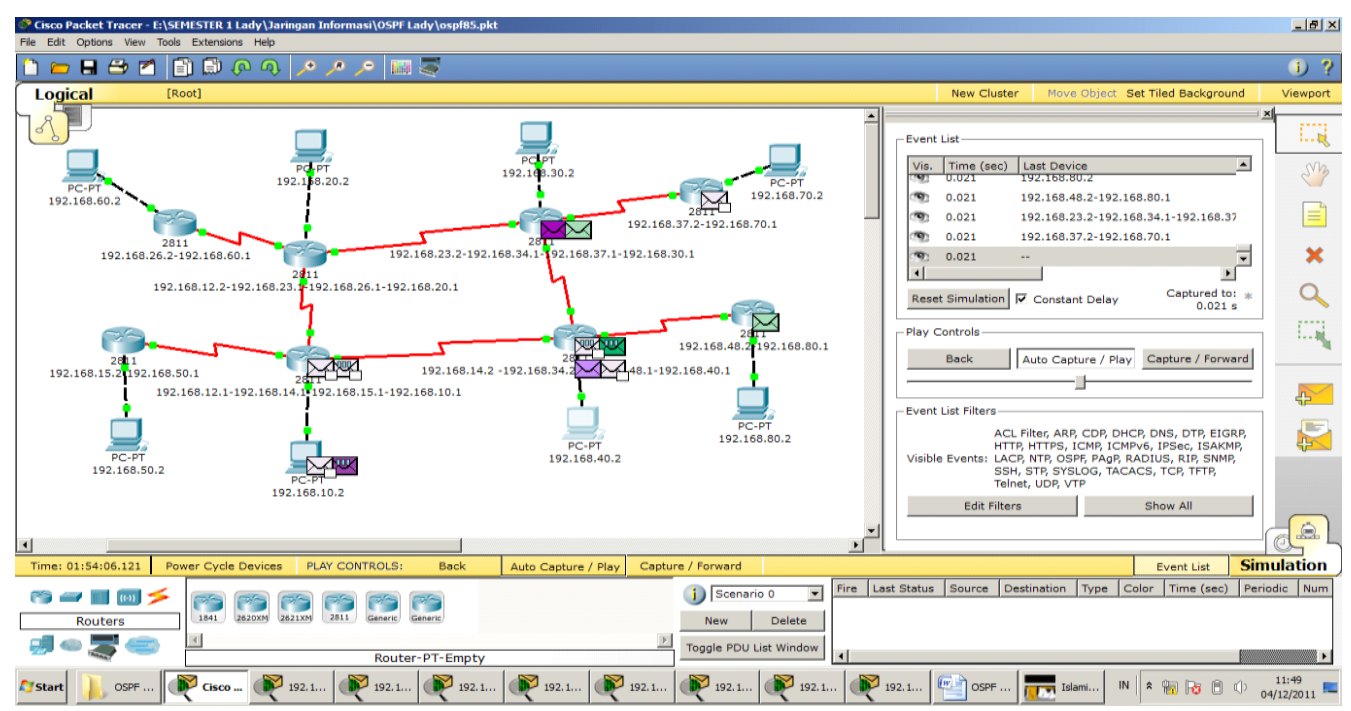

Gambar 9. Traffic load pada Jaringan 
Dari Traffic load, dapat dilihat waktu yang dibutuhkan untuk mengirim paket antar Komputer untuk masing-masing area sebagai berikut:

Tabel 8. Hasil Waktu

\begin{tabular}{|c|c|c|c|c|c|}
\hline Source IP Address & Destination IP Address & \multicolumn{3}{|c|}{ TIME (SECOND) MODEL OSPF } \\
\cline { 3 - 5 } & & 1 Area & 3 Area & 4 Area & 5 Area \\
\hline 192.168 .10 .2 & 192.168 .70 .2 & 0.014 & 0.012 & 0.010 & 0.010 \\
\hline 192.168 .20 .2 & 192.168 .80 .2 & 0.014 & 0.010 & 0.010 & 0.010 \\
\hline 192.168 .30 .2 & 192.168 .10 .2 & 0.010 & 0.010 & 0.006 & 0.008 \\
\hline 192.168 .40 .2 & 192.168 .20 .2 & 0.010 & 0.012 & 0.010 & 0.008 \\
\hline 192.168 .50 .2 & 192.168 .30 .2 & 0.014 & 0.010 & 0.010 & 0.010 \\
\hline 192.168 .60 .2 & 192.168 .40 .2 & 0.014 & 0.014 & 0.014 & 0.010 \\
\hline 192.168 .70 .2 & 192.168 .50 .2 & 0.010 & 0.014 & 0.014 & 0.012 \\
\hline 192.168 .80 .2 & 0.014 & 0.010 & 0.014 & 0.012 \\
\hline \multicolumn{7}{|c|}{ Rata-rata } & $\mathbf{0 . 0 1 2 5}$ & $\mathbf{0 . 0 1 1 5}$ & $\mathbf{0 . 0 1 1}$ & $\mathbf{0 . 0 0 8}$ \\
\hline
\end{tabular}

\section{Penutup}

Dari pengujian diatas, penurunan rata-rata time antara area pada Traffic load untuk Application Ping secara garis besar $0,067 \%$, dan penurunan rata-rata time untuk Application FTP secara garis besar $0,15 \%$. Semakin kecilnya nilai time menunjukkan bahwa pengiriman paket semakin cepat, hal ini menunjukkan bahwa kinerja routing semakin optimal. Maka dapat disimpulkan bahwa semakin banyak area pada jaringan OSPF dan pengelompokan area yang tepat, maka semakin optimal model routing OSPF. Dengan semakin optimal kinerja routing, maka dapat menekan kinerja Processor, Kebutuhan memori dan Konsumsi bandwidth. Oleh karena itu yang terpenting pada jaringan OSPF adalah perancangan topologi jaringan dan konfigurasi routing OSPF yang tepat. Perancangan topologi jaringan yang baik dapat mempengaruhi kinerja sistem secara keseluruhan.

\section{Daftar Pustaka}

Lin, Y.D., Hwang R.H., Baker, F., 2012. Computer Network An Open Source Approuch. McGraw - Hill International Edition.

MikroTik,. 2007. MikroTik RouterOS ${ }^{\mathrm{TM}}$ v2.9 Reference Manual. Mikrotikls SIA.

Parziale, L., Britt, D., Davis, C., Forrester, J., Liu, W., Matthews, C., dan Rosselot, N., 2006. TCP/IP Tutorial and Technical Overview. Redbooks IBM.

Sofana, I., 2008. Membangun Jaringan Komputer, Membuat jaringan Komputer (Wire \& Wireless) Untuk Pengguna Windows dan Linux. Informatika: Bandung.

Syafrizal, M. 2005. Pengantar Jaringan Komputer. Yogyakarta. Andi Publisher: Yogyakarta. 